\title{
Proactive and reactive control by the medial frontal cortex
}

\author{
Veit Stuphorn $^{1,2 *}$ and Erik E. Emeric ${ }^{2}$ \\ ${ }_{1}^{1}$ Psychological and Brain Sciences, The Zanvyl Krieger Mind/Brain Institute, Johns Hopkins University, Baltimore, MD, USA \\ ${ }^{2}$ Neuroscience, The Zanvyl Krieger Mind/Brain Institute, Johns Hopkins University, Baltimore, MD, USA
}

\section{Edited by:}

Giovanni Mirabella, University

of La Sapienza, Italy

Reviewed by:

Birte U. Forstmann, Max Planck

Institute for Human Cognitive and

Brain Sciences, Germany

Vassiliy Tsytsarev, University of

Maryland School of Medicine, USA

*Correspondence:

Veit Stuphorn, The Zanvyl Krieger

Mind/Brain Institute, The Johns

Hopkins University, 3400 N. Charles

Street, 338 Krieger Hall,

Baltimore, MD 21218, USA.

e-mail: veit@jhu.edu
Adaptive behavior requires the ability to flexibly control actions. This can occur either proactively to anticipate task requirements, or reactively in response to sudden changes. Recent work in humans has identified a network of cortical and subcortical brain region that might have an important role in proactive and reactive control. However, due to technical limitations, such as the spatial and temporal resolution of the BOLD signal, human imaging experiments are not able to disambiguate the specific function(s) of these brain regions. These limitations can be overcome through single-unit recordings in non-human primates. In this article, we describe the behavioral and physiological evidence for dual mechanisms of control in response inhibition in the medial frontal cortex of monkeys performing the stop signal or countermanding task.

Keywords: primate, stop signal task, inhibition, supplementary motor area, control

\section{INTRODUCTION}

Adaptive behavior requires the ability to flexibly control actions. This can occur either proactively to anticipate task requirements, or reactively in response to sudden changes. The stop-signal, or countermanding, task is a commonly used behavioral task that requires both forms of behavioral control. It is, therefore, uniquely suited to study the neuronal mechanism of proactive and reactive control.

Recent neuroimaging studies of humans in the stop signal task using manual and eye movements show activation centered on the medial and lateral frontal cortex and subthalamic nucleus (STN; Curtis et al., 2005; Aron and Poldrack, 2006; Li et al., 2006; Aron et al., 2007a). These human imaging results have emphasized critical roles of the supplementary motor cortex (preSMA/SMA), right inferior frontal cortex (IFC), and the STN in response inhibition during a manual stop signal task (reviewed by Aron, 2011). Reactive stopping depends on a fronto-basal ganglia network which includes the preSMA, the IFC, the basal ganglia, and M1. Specifically, it has been suggested that the fast inhibition of a prepared response requires activity of the IFC (Aron et al., 2003). The exact role of the IFC within the proactive inhibition process is debated and may involve the attentional detection of the stop signal and/or a direct role in inhibitory control. Furthermore, it has been suggested that the inhibitory control may be instantiated via hyperdirect input to the basal ganglia via the STN (Aron and Poldrack, 2006). Proactive control also depends on a fronto-basal ganglia network which includes premotor cortex (e.g., preSMA), dorsolateral prefrontal cortex, striatum, and palladium. In this context, inhibitory control may be instantiated via the indirect pathway.

This recent work in humans has identified a network of cortical and subcortical brain region that might have an important role in proactive and reactive control. However, due to technical limitations, such as the spatial and temporal resolution of the BOLD signal, fMRI experiments are not able to disambiguate the specific function(s) of these brain regions. In an ongoing research project we and other labs have, therefore, investigated the role of these frontal areas in behavioral control using single-unit and local field potential recordings in awake, behaving primates performing a countermanding task. In the following we will review some of the insights into the neuronal mechanisms underlying proactive and reactive control that this research has provided.

\section{PROACTIVE AND REACTIVE CONTROL}

Braver $(2007,2012)$ proposed the dual mechanisms of control framework which states that cognitive control operates via two distinct operating modes: proactive control and reactive control. Proactive control is a form of early selection in which goal-relevant information is actively maintained in a sustained manner, before the occurrence of cognitively demanding events, to optimally bias attention, perception, and action systems in a goal-driven manner (Miller and Cohen, 2001). Reactive control is recruited as a late correction mechanism that is mobilized only as needed, in a just-in-time manner, such as after a high interference event is detected (Jacoby et al., 1999). Thus, proactive control relies upon the anticipation and prevention of interference before it occurs, whereas reactive control relies upon the detection and resolution of interference after its onset. Although substantial theoretical and experimental progress toward elucidating the mechanisms underlying reactive inhibitory control has been made (see for example reviews by Stuphorn and Schall, 2002; Schall and Boucher, 2007), the mechanisms underlying proactive control have remained less clear.

\section{THE STOP SIGNAL TASK}

The stop signal or countermanding paradigm (Figure 1) has been used to investigate the neural control of movement initiation and 


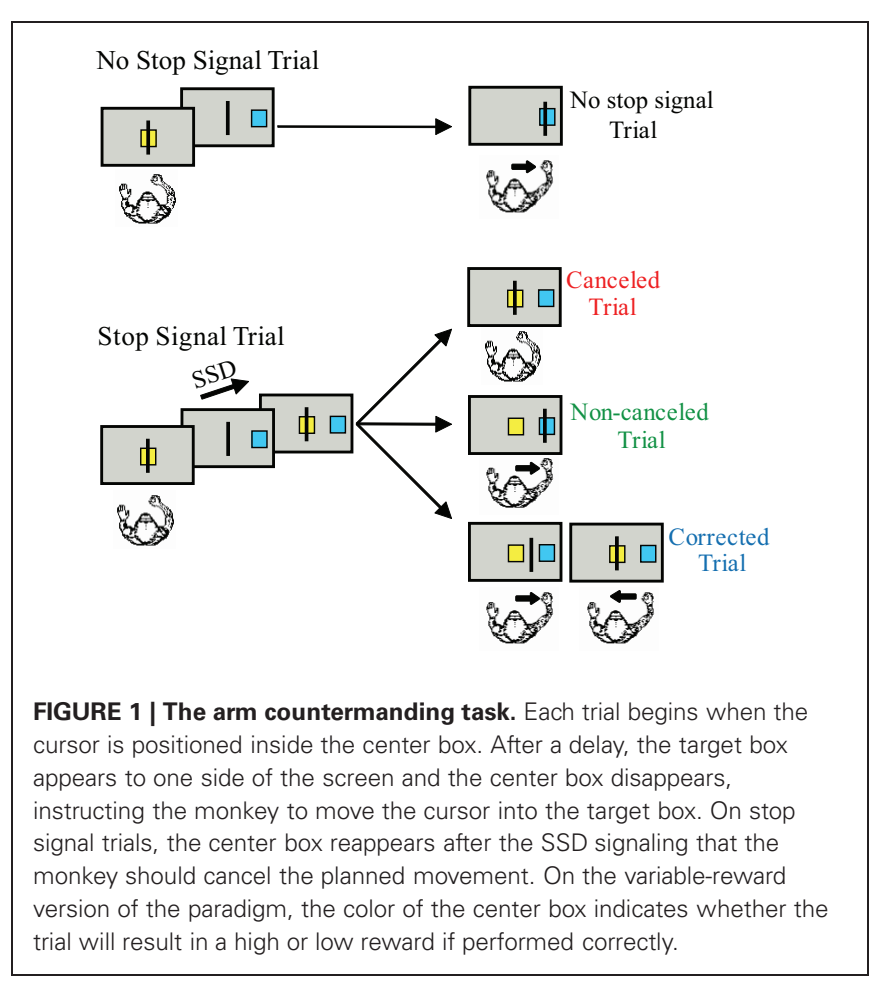

inhibition in rats, awake behaving monkeys, and human subjects (reviewed by Schall and Boucher, 2007). The stop signal paradigm, which includes both a task design and a theoretical construct, was developed to investigate the control of action (reviewed by Logan, 1994). The stop signal paradigm has also been used to examine inhibitory control in a variety of other contexts (reviewed by Verbruggen and Logan, 2008). The stop signal task has also been used to examine patients with ADHD (reviewed by Alderson et al., 2007) and, recently, has been selected for translation for use in clinical trials (Carter et al., 2009).

Although many variations in the stimuli and effectors have been used in the stop signal task, the requirements of the task are quite simple. The stop-signal task probes the ability to control action by requiring subjects to inhibit a planned movement in response to an infrequent stop signal which they do with variable success depending on the delay of the stop signal. Stop signal task performance can be accounted by a race between a process that initiates the movement (GO process) and by one that inhibits the movement (STOP process). This race model provides an estimate of the stop signal reaction time (SSRT), which is the time required to inhibit the planned movement. The SSRT can be estimated using various methods (reviewed by Logan, 1994; Band et al., 2003). T measured in the saccade SSRT average is approximately $100 \mathrm{~ms}$ in monkeys and $130 \mathrm{~ms}$ in humans (e.g., Hanes and Schall, 1995; Hanes and Carpenter, 1999). In the manual stop signal task, the SSRT is an average of $150 \mathrm{~ms}$ in monkeys and $250 \mathrm{~ms}$ in humans (e.g., Boucher et al., 2007; Scangos and Stuphorn, 2010).

The rationale and approach for the race model analysis of the neural stop signal data has been described previously (Logan et al., 1984; Hanes et al., 1998; Hanes and Schall, 1995). Briefly, the chief virtue of the stop signal paradigm is that one can determine whether a neural or motor related signal [e.g., singleunits, local field potentials (LFPs), evoked-potentials (ERPs), electromyograms (EMGs)] is sufficient to control the initiation of movements. The race model imposes two criteria that a signal must meet to play a direct role in the control of movement. First, the signal must be different when a movement is initiated versus when it is inhibited. Second and most important, this difference in activity must evolve before the SSRT elapses. Signals sufficient to control movement initiation are reactive control signals that are exerted in response to the sudden occurrence of a stop signal.

The race model assumes that the GO and STOP processes are stationary stochastic processes with independence between trials. In other words, the response time on the current trial is independent of the preceding trial. However, response times are often non-stationary and non-independent (e.g., Gilden, 2001; Wagenmakers et al., 2004). For example, it is commonly observed across experimental conditions and response modalities that subjects'response times tend to increase in the context of the stop signal task relative to that in simple response time tasks (e.g., Logan, 1981; Logan and Burkell, 1986; van den Wildenberg et al., 2003; Mirabella et al., 2006). Specifically, both short-term and long-term changes in stop-signal frequency lead to behavioral adjustments (Emeric et al., 2007; Nelson et al., 2010). For example, response times decrease after no stop signal trials and increases after stop signal trials. Furthermore, subjects' response times increase and the probability of a cancelled response increases with increasing global proportion of stop signal trials. It seems clear that when stop signal trials occur, subjects proactively adopt a more cautious strategy by slowing responses on subsequent trials.

Importantly, the stop signal task evokes both reactive and proactive forms of control. Although the Braver et al. (2007), Braver (2012) account of control is couched in terms of attentional processes, it can be used as a working hypothesis for investigating the proactive and reactive control processes involved in inhibition. The dual mechanisms of control account provide strong predictions about the temporal dynamics of brain activity related to proactive versus reactive control. Proactive control should be associated with sustained and/or anticipatory activation, which reflects the active maintenance of task goals. This activity may serve as a source of top-down bias that can facilitate processing of expected upcoming events. By contrast, reactive control should be reflected in transient activation subsequent to unexpected events.

\section{NEURAL NETWORK UNDERLYING BEHAVIORAL CONTROL}

A network of brain areas in the frontal cortex and the basal ganglia have been implicated in playing a key role in behavioral control (Floden and Stuss, 2006; Aron et al., 2007b; Picton et al., 2007) and specifically during the stop signal paradigm (Curtis et al., 2005; Aron and Poldrack, 2006; Li et al., 2006; Aron et al., 2007a). A critical component of this network is the medial frontal cortex, in particular the supplementary eye field (SEF), pre-supplementary motor area (pre-SMA), and adjacent 
supplementary motor area (SMA). The SEF is involved in the control of eye movements and provides input to ocular motor structures in the striatum, SC, and brainstem (Huerta and Kaas, 1990). In contrast, the SMA is more important for the control of skeletomotor movements, such as movements of the arm and the hand (Fujii et al., 2002). The role of the pre-SMA is more debated, but seems to be more cognitive than the one of the other two and less clearly related to only one major motor system (Sumner et al., 2007). The pre-SMA and SMA, which are reciprocally connected, differ in their connectivity, with pre-SMA connected to prefrontal cortex but not motor regions, and SMA to motor regions but not prefrontal cortex (Luppino et al., 1991; Tanji, 1996; JohansenBerg et al., 2004). The SEF, pre-SMA, and SMA also provide input to the striatum and STN (Alexander and Crutcher, 1990; Alexander et al., 1990; Nambu et al., 1996). The physiology of the medial frontal areas, as well as the one of other cortical and subcortical regions has been examined for signals sufficient to control movements in monkeys performing the saccade stop signal task (Hanes et al., 1998; Stuphorn et al., 2000, 2010; Paré and Hanes, 2003; Emeric et al., 2008, 2010; Godlove et al., 2011) and skeletomotor (Chen et al., 2010; Scangos and Stuphorn, 2010) stop signal tasks.

\section{REACTIVE CONTROL AND PRIMARY MOTOR AREAS}

In the context of the stop signal task, reactive control is recruited as a late correction mechanism that is mobilized only as needed, in a just-in-time manner, such as the instant a stop signal is perceived. Because this control mechanism is engaged only at short notice, it requires the ability to generate control signals at high speed that are capable of influencing ongoing motor activity even at a late stage of the movement preparation. This form of behavioral control is therefore, likely to be found within and interacting with the primary motor systems that directly control the relevant effectors. Most of the neurophysiological work that has investigated reactive control in monkeys has been concentrated on the oculomotor system, due to the fact that this is the currently best understood motor system (Hanes et al., 1998; Stuphorn et al., 2000; Ito et al., 2003; Paré and Hanes, 2003; but see Scangos and Stuphorn, 2010; Mirabella et al., 2012).

The FEF, located in the rostral bank of the arcuate sulcus in macaque monkeys, participates in the transformation of visual signals into saccade motor commands (reviewed by Schall, 1997). Two of the functional subpopulations of neurons that have been observed in the FEF during gaze shifts are movement and fixation neurons. Movement neurons in the FEF exhibit increased discharge before and during saccades (Goldberg, 1985; Schall, 1991a; Hanes and Schall, 1996) while fixation neurons are active during fixation and exhibit decreased discharge preceding saccades (Hanes et al., 1998; Sommer and Wurtz, 2000). FEF neurons innervate the superior colliculus (Segraves and Goldberg, 1987; Sommer and Wurtz, 2000) and the neural circuit in the brainstem that generates saccades (Segraves, 1992).

Hanes et al. (1998), the first study to apply the race model to single-unit activity during the saccade stop signal task, examined the sufficiency of FEF neurons to control the initiation of saccadic eye movements. Applying the race model to neuronal activity acquired in the context of the stop signal task, provided clear evidence that movement and fixation neurons in FEF generate signals sufficient to control the production of gaze shifts. Saccades were initiated if and only if the activity of FEF movement neurons reach a specific and constant threshold activation level which is independent to the response time (Hanes and Schall, 1996; Brown et al., 2008). Movement neurons, whose activity increased as saccades were prepared, decayed in response to the stop signal before the SSRT elapsed. Fixation cells that decreased firing before saccades exhibited elevated activity in response to the stop signal before the SSRT elapsed. The majority of visual neurons, on the other hand, did not discharge differently when saccades were initiated versus inhibited. The visual neurons that did discharge differentially when saccades were initiated versus inhibited, did so well after the SSRT had elapsed. Paré and Hanes (2003) observed parallel results for visual, movement, and fixation neurons in the superior colliculus (SC).

\section{REACTIVE CONTROL AND MEDIAL FRONTAL CORTEX}

Thus, at least one form of reactive control signals in the oculomotor system is the reactivation of fixation neurons in the FEF and SC. What is driving the onset of these neurons? At least one source is an external event, the onset of the stop signal. Its potency in the oculomotor stop signal task was probably due to the fact that it was a flash of a light in the fovea, which directly activated the gaze fixation system (Everling et al., 1998). However, there are likely to be other, more complex, driving factors. For example, the monkeys initially did not respond to reappearance of the fixation light, or at least not necessarily by inhibition of saccade preparation. This response, and presumably the sensitivity of fixation cells to specific sensory stimuli, was acquired during training. Likewise, even after training, the monkeys did not show saccade inhibition, when outside of the task setting or at the end of the recording session, when their motivation was low. Thus, there is clearly a task set that the monkeys learn during training and that guides their behavior in the stop signal task, when they know that there is a relationship between receiving reward and following certain behavioral rules, i.e., the task set. The representation of task set is a primary function of frontal cortex (Sakai, 2008). We decided, therefore, to study neurons in frontal regions that were hierarchically higher than the primary motor areas and provided input into FEF and SC. The first of the candidate regions that was tested was SEF.

The SEF is an area on the dorsomedial convexivity of the frontal cortex that seems to parallel the FEF in many ways. The activity of neurons in the SEF are modulated by visual or auditory stimuli, while other SEF neurons are modulated preceding and during saccades (e.g., Schall, 1991b; Schlag and Schlag-Rey, 1987. Stuphorn et al. $(2000,2010)$ examined single-unit activity during the saccade stop signal task to determine the sufficiency of SEF neurons to control the initiation of saccadic eye movements. Like the FEF movement neurons, the activity of SEF movement neurons increased as saccades were prepared. However, unlike their counterparts in the FEF, these neurons do not exhibit a reliable threshold and vanishingly few neurons in the SEF generate signals that are sufficient to control gaze (Stuphorn et al., 2000, 2010). Emeric et al. (2010) observed parallel results in the 
event related local field potentials. Importantly, in the current context, no neurons were observed that showed enhanced activity on trial were the monkey successfully cancelled the saccade generation. Thus, SEF does not seem to carry reactive control signals.

Recently, we used the stop signal task to investigate the control of arm movements (Chen et al., 2010; Scangos and Stuphorn, 2010). There are important differences between these two motor systems. For example, unlike saccades, arm movements can be stopped at any point along their path (De Jong et al., 1990). This non-ballistic nature of the arm movements result in differences in the nature of the control signals required compared to the oculomotor system.

Another reason to study SMA and pre-SMA is that they are widely considered to play a completely different role in motor control, than behavioral control. Specifically, it is hypothesized that SMA and pre-SMA are primarily responsible for voluntary movement initiation (Eccles, 1982; Goldberg, 1985; Sumner et al., 2007; Haggard, 2008). This hypothesis was first formulated after the discovery of the readiness potential (RP), a slow negative scalp potential that precedes self-initiated movements in humans (Kornhuber and Deecke, 1965) and whose source has been localized to the pre-SMA (Lang et al., 1991; Ikeda et al., 1999; Yazawa et al., 2000). Single-unit recordings in monkeys have shown that the pre-SMA and SMA contain long-lead neurons that become active up to $2 \mathrm{~s}$ before the initiation of self-paced movements (Okano and Tanji, 1987) and that pre-SMA neurons signal the initiation of action in a time-selective manner (Mita et al., 2009). In addition, lesion studies indicate an important role of SMA in inhibition, as well (Sumner et al., 2007). Thus, there are at least two different hypotheses in the literature concerning the role of pre-SMA and SMA in motor control. The experiments mentioned above have demonstrated that the earliest activity related to movements arises in the pre-SMA and SMA, but does this activity play a causal role in movement initiation or is this activity related to reactive or proactive control?

Scangos and Stuphorn (2010) probed SMA and pre-SMA movement related neurons with a manual version of the stop signal paradigm and vanishingly few neurons provided signals sufficient to control movement initiation according to the logic of the stop signal paradigm (Figure 2A). However, a second group of neurons, similar to the FEF/SC fixation neurons, were more active during successful response inhibition. A minority of these cells responded early enough to be able to influence the inhibition of the movement (Figure 2B). Thus, a minority of SMA/preSMA neurons may play a role in movement inhibition but do not appear to control movement initiation.

Chen et al. (2010) examined the local field potentials that were acquired simultaneously with the SMA single-units for signals sufficient to control the initiation of arm movements. Unlike the single-units, there were significant differences in LFP power in a number of frequency bands, which correlated with the successful inhibition of the arm movement. In the beta band $(5-20 \mathrm{~Hz})$ there was an increase in power evoked by the stop signal which persisted long after the SSRT elapsed. Within the high gamma band $(130-140 \mathrm{~Hz})$, especially for planned contralateral movements, there was an increase of power immediately after the

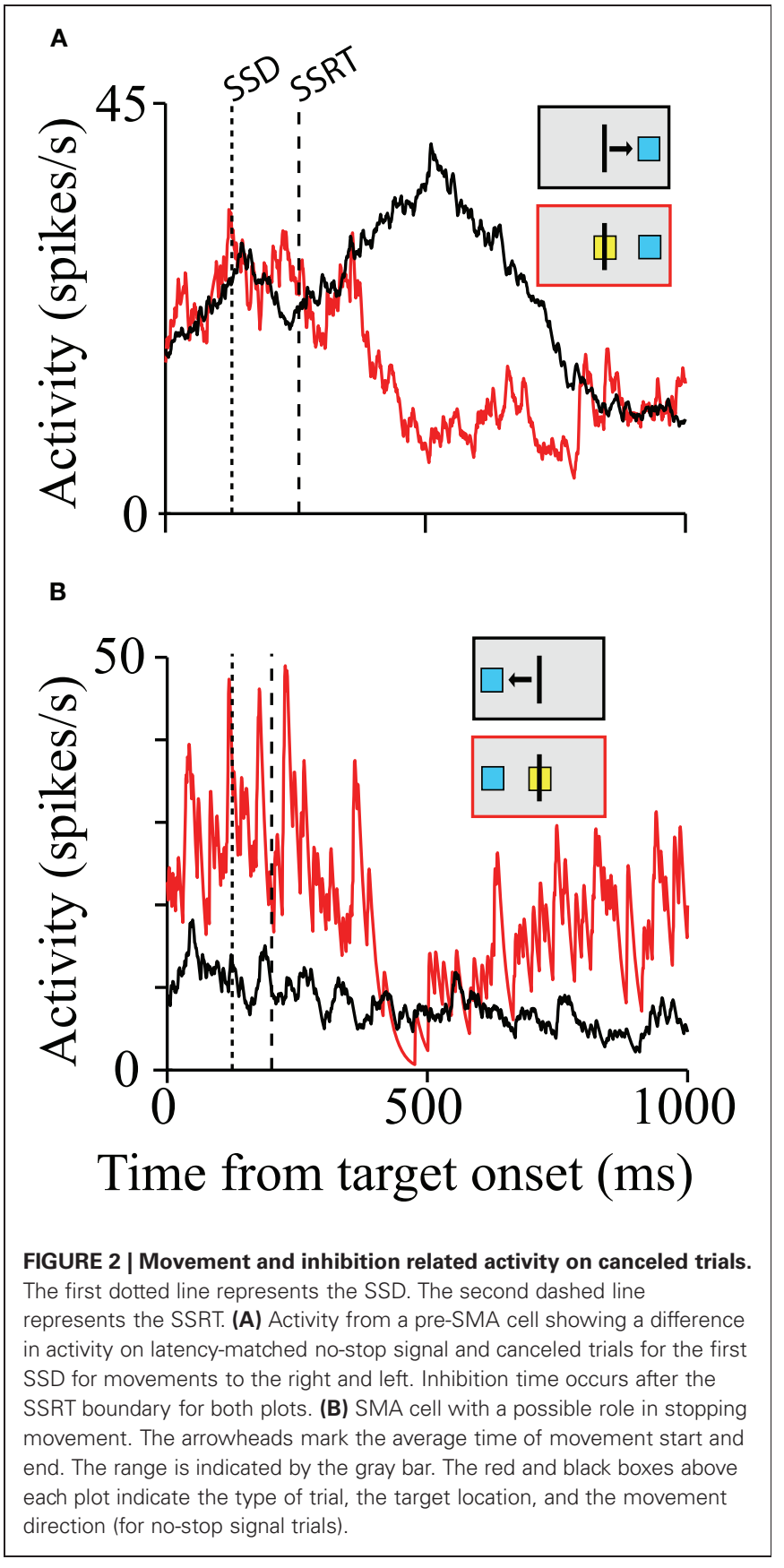

stop signal and before the SSRT. Importantly, the modulation of LFP power in both recordings clearly started before the SSRT. This indicates that the neuronal processes that underlie the changes in LFP power in the respective parts of pre-SMA and SMA were sufficient to reactively control the inhibition of arm movements.

The evidence we have discussed thus far suggests that, of all the brain areas probed with the stop signal paradigm, only the neurons in the FEF, SC, and pre-SMA/SMA carry signals sufficient to control movement initiation and thus provide signals consistent with reactive control. These findings show a potential functional difference between the control of the oculomotor 
system (through SEF) and control of the skeletomotor system (through pre-SMA/SMA). In the oculomotor system reactive control signals are found on the level of the primary motor areas, but not in medial frontal cortex. In contrast, in the skeletomotor system the medial frontal cortex participates in reactive control. There is a number of considerations and possible interpretations of these findings.

First, it is possible that the reactive control signals exist in the SEF, but were simply overlooked in past recording experiments. That is always possible, but the fact that the negative finding in SEF is based on results in four monkeys, while the positive finding in pre-SMA/SMA is based on results in only two monkeys, makes this possibility less likely.

Second, it is possible that this finding reflects a real difference in the structure and organization of behavioral control. The number of cortical areas dedicated to the control of skeletomotor movements and their relative size is much larger than the ones of cortical areas dedicated to oculomotor control (e.g., Geyer et al., 2000). This likely reflects the fact that the dynamics and kinematic of skeletomotor movements are far more complex than saccadic eye movements. Therefore, it might not be surprising, that primary motor regions, such as FEF and SC, are sufficient for the reactive control of saccades, while in the case of skeletomotor movements it is necessary to recruit or involve medial frontal cortex as well.

Finally, one should keep in mind that the investigation and comparison of the oculo- and skeletomotor system is still incomplete. Mirabella et al. (2011) tested dorsal premotor cortex (PMd) using a variant stop signal task where the monkeys responded to visual targets by touch with a speeded reaching movement. The study found that among neurons with a movement-preparatory activity, about one-third exhibit a modulation before the behavioral estimate of the time it takes to cancel a planned movement. Hence these neurons exhibit a pattern of activity suggesting that PMd plays a critical role in the control of arm movement initiation and suppression. Some PMd neurons in the study were specifically active, when the monkeys were cancelling the arm movement. This is an intriguing finding, but a number of technical difficulties, such as the absence of EMG recordings limit the interpretation of neural activity as clear evidence of reactive control signals. Furthermore, there is currently no single-unit study of M1 using the stop signal task.

The location of the final decision as to whether or not a planned arm movement is carried out is, therefore, still not known. One possibility is that it takes place in the premotor or in the primary motor cortex (M1). A recent countermanding study in humans found that in M1, corticomotor excitability was reduced and intracortical inhibition was significantly greater on Stop trials compared with No stop signal trials at a time that preceded the onset of muscle activity (Coxon et al., 2006). These results indicate that inhibitory networks within M1 might contribute to volitional inhibition of prepared action. Another possible location for the final decision could be the basal ganglia (Mink, 1996). The internal segment of the globus pallidus (GPi) inhibits thalamic and cortical neurons, and thus serves as a block on the initiation of any action. The direct pathway through the striatum releases an action by inhibiting a specific set of GPi neurons. Both the hyperdirect pathway through the STN and the indirect pathway from the striatum through the external segment of the globus pallidus suppress actions by more wide-spread excitation of GPi (Mink, 1996; Nambu, 2004). A recent human neuroimaging study provided evidence for a role of the STN and the hyperdirect pathway in countermanding (Aron and Poldrack, 2006). Furthermore, deep brain stimulation of STN affects response inhibition in Parkinson's patients (Mirabella et al., 2012).

\section{THE STOP SIGNAL TASK: PROACTIVE CONTROL}

Proactive control adjusts the response selection and preparation process in anticipation of known task demands. Proactive control is guided by endogenous signals, instead of external triggers, and is constantly present throughout response selection and preparation. It can reflect a variety of factors such as the incentives for choosing different responses, and the frequency of task-relevant events. In the context of the stop signal task, proactive control is mostly related to a regulation of the level of excitability of the motor system. By adjusting the level of excitation and inhibition of the motor system, the proactive control system sets the threshold for initiating a response. In making these adjustments the proactive system has to negotiate the tradeoff between speed (reaction time) and accuracy (cancelation likelihood) (Bogacz et al., 2010).

Task performance in the stop signal task is clearly influenced by factors that are independent of the presence of an actual stop signal (Verbruggen and Logan, 2009). Behavioral studies in monkeys and humans show that the mean response time during no stop signal trials is delayed relative to a situation when no stop signal is expected (Verbruggen et al., 2004; Stuphorn and Schall, 2006; Verbruggen et al., 2006). Short-term changes in stop signal frequency lead to behavioral adjustments (Emeric et al., 2007; Mirabella et al., 2008; Chen et al., 2010; Nelson et al., 2010). These systematic modulations in the mean reaction time indicate the presence of proactive control.

While the experimental evidence in favor of a role of the medial frontal cortex in reactive control was mixed, there is very clear evidence for such a role in the case of proactive control. Very few neurons carried signals sufficient for saccade initiation (Stuphorn et al., 2010). However, there exists a more subtle relationship between SEF activation and saccade production. The activity of some SEF neurons was correlated with response time and varied with sequential adjustments in response latency. Trials in which monkeys inhibited or produced a saccade in a stop signal trial were distinguished by a modest difference in discharge rate of these SEF neurons before stop signal or target presentation. Parallel results were observed in the SMA (Chen et al., 2010). Furthermore, the analysis of LFP in the SMA showed that longer response times following stop signal trials (Figure 3A) were accompanied by an increased power in the very low-frequency $(1-20 \mathrm{~Hz})$ and the beta band $(25-40 \mathrm{~Hz})$ starting approximately $120 \mathrm{~ms}$ before target onset (Figure 3B). These findings indicate that neurons in the SEF and pre-SMA/SMA, in contrast to FEF/SC movement and fixation cells, do not contribute directly and immediately to the initiation of visually guided saccades. However the SEF, pre-SMA, and SMA may 


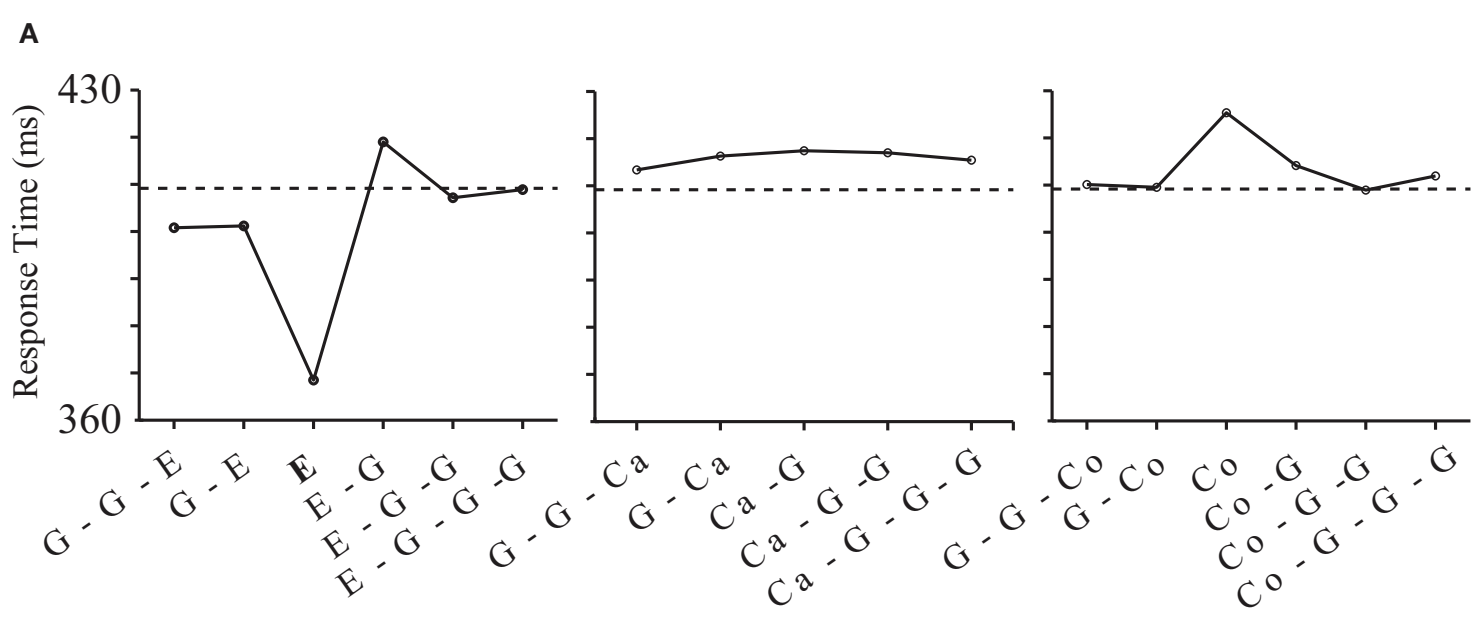

B

Trials Type

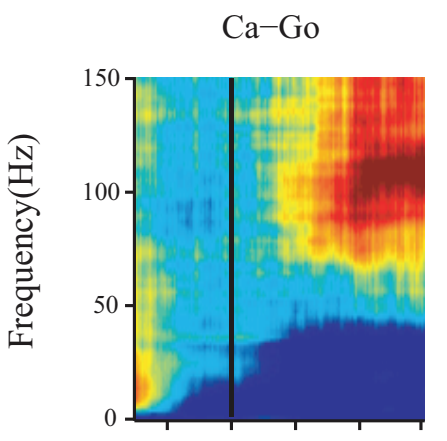

E-Go

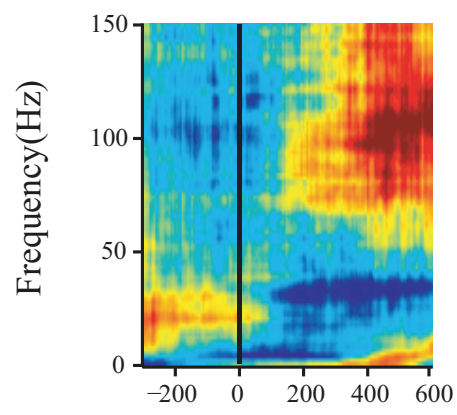

Go-Go

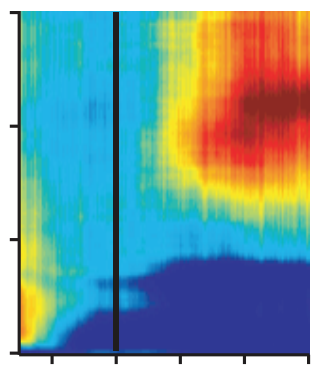

Go-Go

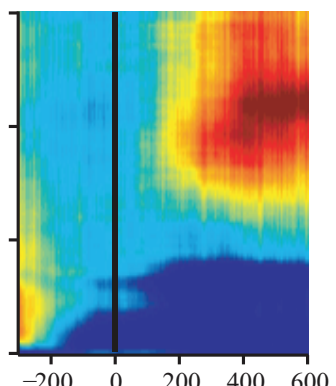

Time from target onset (ms)

(dB)

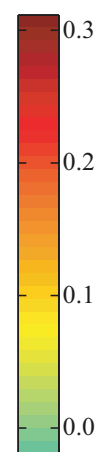

$-0.1$
$[\mathrm{Ca}-\mathrm{Go}]-[\mathrm{Go}-\mathrm{Go}]$

$(\mathrm{dB})$
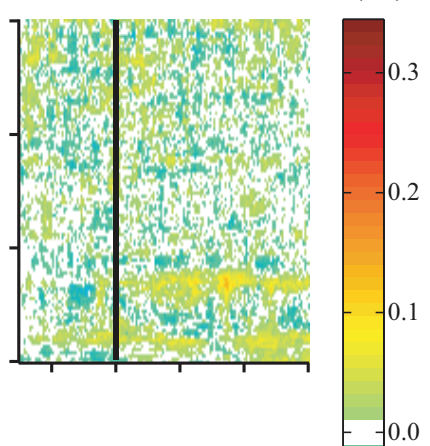

$[\mathrm{E}-\mathrm{Go}]-[\mathrm{Go}-\mathrm{Go}]$

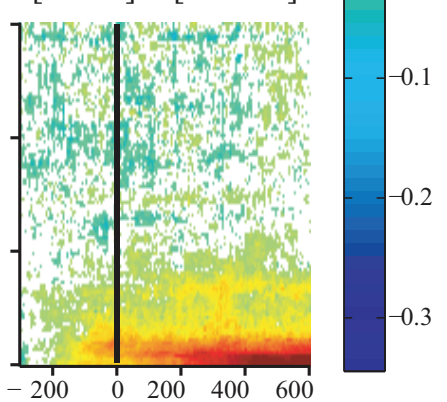

FIGURE 3 | Changes in LFP power predict arm movement inhibition.

Effects of trial history on response time. (A) Response times for no-stop-signal and stop trials surrounding noncanceled trials (left), trials surrounding canceled trials (middle), and trials surrounding corrected trials (right). The type of trials to which the response time corresponds to is shown in bold (G: no stop signal; E: noncanceled; Ca: canceled; Co: corrected). The dotted line indicates the average response time on no-stop-signal trials. (B) Effects of trial history on LFP power in the SMA. Comparison was performed between three groups of no-stop-signal trials: those that followed another canceled trial (Ca-Go), those that followed a noncanceled error trial (E-Go), and those that followed a go trial (Go-Go). The time-frequency maps are aligned on target onset. The significant differences between them are shown in the right panel. proactively regulate movement initiation by adjusting the level of excitation and inhibition of the occulomotor and skeletomotor systems based on prior performance and anticipated task requirements.

\section{REGULATION OF SPEED-ACCURACY TRADEOFF BY MEDIAL} FRONTAL CORTEX

In terms of computational reaction time models, a change in the responsiveness of the motor system translates into a shift of the 
distance to the threshold at which a response is initiated (Ratcliff, 1978; Luce, 1986; Reddi and Carpenter, 2000). A decrease of the threshold is equivalent to an increase of the baseline, and vice versa (Stuphorn and Schall, 2002; Bogacz et al., 2010). Such shifts can explain speed-accuracy tradeoffs (Uchida et al., 2006). The results of neurophysiological experiments fit such reaction time models very well. The firing rate of neurons in the oculomotor (Hanes and Schall, 1996) and skeletomotor system (Lecas et al., 1986) indeed exceeds a fixed threshold, when movements are initiated. There is also some evidence for changes in baseline activity in the oculomotor system. In the superior colliculus, neurons with visual and saccade-related activity increase their baseline firing rate with increasing probability that a saccade in their motor field is required (Basso and Wurtz, 1998; Dorris and Munoz, 1998) or is more rewarding (Isoda and Hikosaka, 2008a,b).

We propose here that the dorsomedial frontal cortex, including the SMA, is the source of the proactive control signal that modulates the baseline motor activity. This hypothesis is supported by the fact that activity levels in and around the pre-SMA increased when response speed is emphasized during speed-accuracy tradeoff experiments (Forstmann et al., 2008; Ivanoff et al., 2008; van Veen et al., 2008).

The hypothesis that movement-related neurons in SEF, preSMA, and SMA influence reaction time by controlling excitability in the oculomotor and skeletomotor system, respectively, might be seen as contradicting the finding that these same neurons do not carry signals sufficient to control movement initiation (Scangos and Stuphorn, 2010; Stuphorn et al., 2010). However, this is not the case. We propose that SMA activity determines the response threshold, i.e., the amount of rise in motor activity that is necessary to initiate a movement. While the distance to the threshold clearly influences the average time at which it is exceeded, it is not sufficient to fully determine whether and when the threshold is actually exceeded. We propose that this process takes place in M1 and FEF, while SMA and SEF modulates this process by setting the urgency with which a movement is chosen and executed.

\section{MOTIVATION FOR SPECIFIC ACTIONS AND ITS RELATIONSHIP TO PROACTIVE CONTROL}

While our findings make it unlikely that pre-SMA and SMA play a causal role in initiating movements, lesions in these areas do have a profound influence on behavior. We found that the activity of most movement-related neurons in SMA and SEF was very strongly influenced by the reward contingency of the action (Scangos and Stuphorn, 2010; So and Stuphorn, 2010). Thus, SEF, pre-SMA, and SMA might represent the urge to act in a specific way rather than the commitment to do so. According to this interpretation the neurons in the medial frontal cortex represent a map of action values.

This interpretation of medial frontal cortex activity as motivation signal fits with a large number of lesion and recording studies in humans and monkeys that indicate that the medial frontal cortex, in particularly pre-SMA, is responsible for selfgenerated, voluntary actions (Papa et al., 1991; Romo and Schultz, 1992; Deiber et al., 1999), and reflects the reward obtained by these actions (Stuphorn et al., 2000; Ito et al., 2003; Roesch and
Olson, 2003, 2004; Campos et al., 2005; Sohn and Lee, 2007). Voluntary behavior is characterized by the motivation to act in order to obtain a particular goal. Lesions of the pre-SMA and SMA may lead to apathy, because the motivational drive that normally links reward expectation with specific actions is absent. However, since the motor system is still functional, external stimuli may still trigger automatic or habitual movements. This is, in fact, what is observed for SMA lesions in monkeys (Thaler et al., 1988, 1995) and humans (Levy and Dubois, 2006; Schmidt et al., 2008).

There exists a close relationship between this interpretation of medial frontal cortex activity as a motivational signal to the earlier discussed interpretation that the activity might represent proactive control signals. From an motivational point of view, there are two mutually exclusive motivations that compete with each other in the stop signal task. First, there is a motivation to GO resulting from the very frequent link between movement exceution and reward delivery. Secondly, there is a motivation to WAIT (not to stop per se) generated by the awareness that on any given trial a stop signal might be given. These two motivations (or action values for GO and WAIT) vary in strength according to the most recent reward and trial history. The relative strength of these motivations determines the level of excitability and the momentary speed-accuracy tradeoff of the subject at any moment in the task. However, this changing modulation of the level of excitability of the motor system was exactly what was discussed as a proactive control system earlier.

Our behavioral data showed strong sequential effects of errors and successful cancelations on the reaction time of arm movements in the stop signal task. Errors or an increased frequency of stop signal trials lead to longer reaction times on subsequent trials. Fewer stop signal trials lead to shorter reaction times. The reaction time reflects the level of responsiveness in the motor system. A less excitable state leads to longer reaction times, while a more excitable state leads to shorter reaction times. The sequential effects show that the state of responsiveness of the motor system is constantly adjusted by control signals that reset the balance of excitation and inhibition within the motor system.

We observe motivational signals in SEF, pre-SMA, and SMA during movement generation. In contrast, activity in the orbitofrontal cortex appears earlier, immediately after a cue indicating potential reward is revealed (Tremblay and Schultz, 1999; Roesch and Olson, 2003, 2004; Padoa-Schioppa and Assad, 2006), but it does not encode the action necessary to obtain the reward (Wallis and Miller, 2003; Padoa-Schioppa and Assad, 2006). Lateral prefrontal cortex activity reflects reward size and preference in the delay period before a response is made (Kobayashi et al., 2006; Sakagami and Watanabe, 2007). Striatal activity arises after a cue is presented and remains high until reward is delivered (Hikosaka et al., 1989; Hollerman et al., 1998). Thus, early reward related signals from other brain areas might feed into the SMA and pre-SMA where they are transformed into incentive signals for specific actions (So and Stuphorn, 2010).

\section{COMPARISON OF HUMAN AND MONKEY DATA}

Taken as a whole, electrophysiological data from humans and monkeys during stopping point to comparable proactive and 
reactive control mechanisms. The preSMA and STN become more active when a prepotent response must be reactively inhibited (Isoda and Hikosaka, 2007, 2008a,b), while the preSMA and SMA activity is correlated with subsequent proactive changes in response time (Chen et al., 2010; Stuphorn et al., 2010). These findings fit well with the results of human studies (Aron and Poldrack, 2006; Sharp et al., 2010).

In addition, Aron and Poldrack (2006) have used human imaging results to emphasize the role of the right IFC and the STN in response inhibition during a manual stop signal task. Area 45, the cortex anterior to the inferior spur of the arcuate sulcus and lateral to the principal sulcus, is the most likely monkey homolog of the rIFG (Petrides and Pandya, 1999). Unfortunately, only very few electrophysiological recording studies in monkeys have examined neurons in area 45 in tasks requiring inhibition. These studies have used a go/nogo task and have reported neurons in BA45 that responded to behaviorally relevant cues and identified them as nogo signals (Sakagami et al., 2001). However, no activity was reported during the time period when the response to the target needed to be suppressed. Clearly, neurophysiological studies in monkeys are necessary to validate the role of IFC in stopping.
Aron et al. (2007a) used diffusion-weighted imaging tractography to show that the IFC and the STN region are connected via a white matter tract, which could underlie a hyperdirect pathway for basal ganglia control. Although, the corticocortical and thalamocortical connections of area 45 have been identified in the monkey (Contini et al., 2010; Gerbella et al., 2010), there have been no anatomical studies describing a hyperdirect projection from area 45 to the STN (e.g., Monakow et al., 1978). The existence of a hyperdirect connection between IFC/area 45 and STN is critical for the role of ICF in reactive stopping (Aron, 2011). It is therefore, of great priority to verify the existence of such a projection in monkeys.

\section{CONCLUSION}

Converging evidence from human imaging and monkey electrophysiology during stopping point to comparable proactive and reactive control mechanisms. However the exact function al role of IFC, basal ganglia, and thalamus in stopping is still unclear and will require further investigations using neurophysiological in awake behaving monkeys.

\section{REFERENCES}

Alexander, G. E., and Crutcher, M. D. (1990). Functional architecture of basal ganglia circuits: neural substrates of parallel processing. Trends Neurosci. 13, 266-271.

Alexander, G. E., Crutcher, M. D., and DeLong, M. R. (1990). Basal ganglia-thalamocortical circuits: parallel substrates for motor, oculomotor, "prefrontal" and "limbic" functions. Prog. Brain Res. 85, 119-146.

Alderson, R. M., Rapport, M. D., and Koer, M. J. (2007). Attentiondeficit/hyperactivity disorder and behavioral inhibition: a metaanalytic review of the stop-signal paradigm. J. Abnorm. Child Psychol. 35, 745-758.

Aron, A. R., Fletcher, P. C., Bullmore, E. T., Sahakian, B. J., and Robbins, T. W. (2003). Stop-signal inhibition disrupted by damage to right inferior frontal gyrus in humans. Nat. Neurosci. 6, 115-116.

Aron, A. R. (2011). From reactive to proactive and selective control: developing a richer model for stopping inappropriate responses. Biol. Psychiatry 69, e55-e68.

Aron, A. R., and Poldrack, R. A. (2006). Cortical and subcortical contributions to stop signal response inhibition: role of the subthalamic nucleus. J. Neurosci. 26, 2424-2433.

Aron, A. R., Behrens, T. E., Smith, S., Frank, M. J., and Poldrack,
R. A. (2007a). Triangulating a cognitive control network using diffusion-weighted magnetic resonance imaging (mri) and functional mri. J. Neurosci. 27, 3743-3752.

Aron, A. R., Durston, S., Eagle, D. M., Logan, G. D., Stinear, C. M., and Stuphorn, V. (2007b). Converging evidence for a fronto-basal-ganglia network for inhibitory control of action and cognition. J. Neurosci. 27, 11860-11864.

Band, G. P. H., van der Molen, M. W., and Logan, G. D. (2003). Horserace model simulations of the stop-signal procedure. Acta Psychol. (Amst.) 112, 105-142.

Basso, M. A., and Wurtz, R. H. (1998). Modulation of neuronal activity in superior colliculus by changes in target probability. J. Neurosci. 18, 7519-7534.

Bogacz, R., Wagenmakers, E. J., Forstmann, B. U., and Nieuwenhuis, S. (2010). The neural basis of the speed-accuracy tradeoff. Trends Neurosci. 33, 10-16.

Boucher, L., Stuphorn, V., Logan, G. D., Schall, J. D., and Palmeri, T. J. (2007). Stopping eye and hand movements: are the processes independent? Percept. Psychophys. 69, 785-801.

Braver, T. S. (2012). The variable nature of cognitive control: a dual mechanisms framework. Trends Cogn. Sci. 16, 106-113.

Braver, T., Gray, J., and Burgess, G. (2007). "Explaining the many varieties of working memory variation: dual mechanisms of cognitive control," in Variation in Working Memory, eds A. Conway, C. Jarrold, M. Kane, A. Miyake, and J. Towse (Oxford: Oxford University Press) 76-106

Brown, J. W., Hanes, D. P., Schall, J. D., and Stuphorn, V. (2008). Relation of frontal eye field activity to saccade initiation during a countermanding task. Exp. Brain Res. 190, 135-151.

Campos, M., Breznen, B., Bernheim, K., and Andersen, R. A. (2005). Supplementary motor area encodes reward expectancy in eyemovement tasks. J. Neurophysiol. 94, 1325-1335.

Carter, C. S., Barch, D. M., Gur, R., Gur R., Pinkham, A., and Ochsner, K (2009). CNTRICS final task selection: social cognitive and affective neuroscience-based measures. Schizophr. Bull. 35, 153-162.

Chen, X., Scangos, K. W. and Stuphorn, V. (2010). Supplementary motor area exerts proactive and reactive control of arm movements. J. Neurosci. 30, 14657-14675.

Contini, M., Baccarini, M., Borra E., Gerbella, M., Rozzi, S., and Luppino, G. (2010). Thalamic projections to the macaque caudal ventrolateral prefrontal areas 45a and 45b. Eur. J. Neurosci. 32, 1337-1353.

Coxon, J. P., Stinear, C. M., and Byblow, W. D. (2006). Intracortical inhibition during volitional inhibition of prepared action. J Neurophysiol. 95, 3371-3383.

Curtis, C. E., Cole, M. W., Rao, V. Y., and D'Esposito, M. (2005). Canceling planned action: an fmri study of countermanding saccades. Cereb. Cortex 15 1281-1289.

De Jong, R., Coles, M. G., Logan, G. D., and Gratton, G. (1990). In search of the point of no return: the control of response processes. J. Exp. Psychol. Hum. Percept. Perform. 16, 164-182.

Deiber, M. P., Honda, M., Ibaez, V., Sadato, N., and Hallett, M. (1999). Mesial motor areas in self-initiated versus externally triggered movements examined with fmri: effect of movement type and rate. J. Neurophysiol. 81 , 3065-3077.

Dorris, M. C., and Munoz, D. P. (1998). Saccadic probability influences motor preparation signals and time to saccadic initiation. J. Neurosci. 18, 7015-7026.

Eccles, J. C. (1982). The initiation of voluntary movements by the supplementarymotor area. Arch. Psychiatr. Nervenkr. 231, 423-441.

Emeric, E. E., Brown, J. W., Boucher, L., Carpenter, R. H. S., Hanes, D. P., Harris, R., Logan, G. D., Mashru, R. N., Paré, M., Pouget, P., Stuphorn, V., Taylor, T. L., and Schall, J. D. (2007). Influence of history on saccade countermanding performance in humans and 
macaque monkeys. Vis. Res. 47, 35-49.

Emeric, E. E., Brown, J. W., Leslie, M., Pouget, P., Stuphorn, V., and Schall, J. D. (2008). Performance monitoring local field potentials in the medial frontal cortex of primates: anterior cingulate cortex. J. Neurophysiol. 99, 759-772.

Emeric, E. E., Leslie, M., Pouget, P., and Schall, J. D. (2010). Performance monitoring local field potentials in the medial frontal cortex of primates: supplementary eye field. J. Neurophysiol. 104, 1523-1537.

Everling, S., Par, M., Dorris, M. C., and Munoz, D. P. (1998). Comparison of the discharge characteristics of brain stem omnipause neurons and superior colliculus fixation neurons in monkey: implications for control of fixation and saccade behavior. J. Neurophysiol. 79, 511-528.

Floden, D., and Stuss, D. T. (2006). Inhibitory control is slowed in patients with right superior medial frontal damage. J. Cogn. Neurosci. $18,1843-1849$

Forstmann, B. U., Dutilh, G., Brown, S., Neumann, J., von Cramon, D. Y., Ridderinkhof, K. R., and Wagenmakers, E. J. (2008). Striatum and preSMA facilitate decision-making under time pressure. Proc. Natl. Acad. Sci. U.S.A. 105, 17538-17542.

Fujii, N., Mushiake, H., and Tanji, J. (2002). Distribution of eye- and arm movement-related neuronal activity in the SEF and in the SMA and pre-SMA of monkeys. J. Neurophysiol. 87, 2158-2166.

Gerbella, M., Belmalih, A., Borra, E., Rozzi, S., and Luppino, G. (2010). Cortical connections of the macaque caudal ventrolateral prefrontal areas $45 \mathrm{a}$ and 45b. Cereb. Cortex 20, 141-168.

Geyer, S., Matelli, M., Luppino, G., and Zilles, K. (2000). Functional neuroanatomy of the primate isocortical motor system. Anat. Embryol. (Berl.) 202, 443-474.

Gilden, D. L. (2001). Cognitive emissions of 1/f noise. Psychol. Rev. 108, 33-56.

Godlove, D. C., Emeric, E. E., Segovis, C. M., Young, M. S., Schall, J. D., and Woodman, G. F. (2011). Event-related potentials elicited by errors during the stop-signal task. I. macaque monkeys. J. Neurosci. 31, 15640-15649.

Goldberg, G. (1985). Supplementary motor area structure and function: review and hypotheses. Behav. Brain Sci. 8, 567-588.
Haggard, P. (2008). Human volition: towards a neuroscience of will. Nat. Rev. Neurosci. 9, 934-946.

Hanes, D. P., and Carpenter, R. H. (1999). Countermanding saccades in humans. Vis. Res. 39, 2777-2791.

Hanes, D. P., and Schall, J. D. (1995). Countermanding saccades in macaque. Vis. Neurosci. 12, 929-937.

Hanes, D. P., and Schall, J. D. (1996). Neural control of voluntary movement initiation. Science 274, 427-430.

Hanes, D., Patterson, W., and Schall, J. (1998). Role of frontal eye fields in countermanding saccades: visual, movement, and fixation activity. J. Neurophysiol. 79, 817.

Hikosaka, O., Sakamoto, M., and Usui, S. (1989). Functional properties of monkey caudate neurons. III. Activities related to expectation of target and reward. J. Neurophysiol. 61, 814-832.

Hollerman, J. R., Tremblay, L., and Schultz, W. (1998). Influence of reward expectation on behaviorrelated neuronal activity in primate striatum. J. Neurophysiol. 80, 947-963.

Huerta, M. F., and Kaas, J. H. (1990). Supplementary eye field as defined by intracortical microstimulation: connections in macaques. J. Comp. Neurol. 293, 299-330.

keda, A., Yazawa, S., Kunieda, T., Ohara, S., Terada, K., Mikuni, N., Nagamine, T., Taki, W., Kimura, J., and Shibasaki, H. (1999). Cognitive motor control in human pre-supplementary motor area studied by subdural recording of discrimination/selection-related potentials. Brain 122, 915-931.

Isoda, M., and Hikosaka, O. (2007). Switching from automatic to controlled action by monkey medial frontal cortex. Nat. Neurosci. 10, 240-248.

Isoda, M., and Hikosaka, O. (2008a). A neural correlate of motivational conflict in the superior colliculus of the macaque. J. Neurophysiol. 100, 1332-1342.

Isoda, M., and Hikosaka, O. (2008b). Role for subthalamic nucleus neurons in switching from automatic to controlled eye movement. J. Neurosci. 28, 7209-7218.

Ito, S., Stuphorn, V., Brown, J. W., and Schall, J. D. (2003). Performance monitoring by the anterior cingulate cortex during saccade countermanding. Science 302, 120-122.

Ivanoff, J., Branning, P., and Marois, R. (2008). Fmri evidence for a dual process account of the speed-accuracy tradeoff in decisionmaking. PLoS ONE 3:e2635. doi: 10.1371/journal.pone.0002635

Jacoby, L., Kelley, C., and Mcelree, B. (1999). "The role of cognitive control: early selection versus late correction," in Dual Process Theories in Social Psychology, eds S. Chaiken and Y. Trope (New York, NY: Guilford Press), 383-400.

Johansen-Berg, H., Behrens, T. E. J., Robson, M. D., Drobnjak, I., Rushworth, M. F. S., Brady, J. M., Smith, S. M., Higham, D. J., and Matthews, P. M. (2004). Changes in connectivity profiles define functionally distinct regions in human medial frontal cortex. Proc. Natl. Acad. Sci. U.S.A. 101, 13335-13340.

Kobayashi, S., Nomoto, K., Watanabe, M., Hikosaka, O., Schultz, W., and Sakagami, M. (2006). Influences of rewarding and aversive outcomes on activity in macaque lateral prefrontal cortex. Neuron 51, 861-870.

Kornhuber, H. H., and Deecke, L. (1965). Hirnpotentialägnderungen bei Willkürbewegungen und passiven Bewegungen des Menschen: Bereitschaftspotential und reafferente potentiale. Pflügers Arch. 284 $1-17$.

Lang, W., Cheyne, D., Kristeva, R., Beisteiner, R., Lindinger, G. and Deecke, L. (1991). Threedimensional localization of sma activity preceding voluntary movement. A study of electric and magnetic fields in a patient with infarction of the right supplementary motor area. Exp. Brain Res. 87, 688-695.

Lecas, J. C., Requin, J., Anger, C., and Vitton, N. (1986). Changes in neuronal activity of the monkey precentral cortex during preparation for movement. J. Neurophysiol. 56, 1680-1702.

Levy, R., and Dubois, B. (2006). Apathy and the functional anatomy of the prefrontal cortex-basal ganglia circuits. Cereb. Cortex 16 916-928.

Li, C. S. R., Huang, C., Constable, R. T., and Sinha, R. (2006). Imaging response inhibition in a stop-signal task: neural correlates independent of signal monitoring and postresponse processing. J. Neurosci. 26, 186-192.

Logan, G. (1981). "Attention, automaticity, and the ability to stop a speeded choice response," in Attention and Performance IX, eds J. Long and A. D. Baddeley (Hillsdale, NJ: Erlbaum), 205-222.
Logan, G. D. (1994). "On the abilty to inhibit thought and action: a user's guide to the stop signal paradigm," in Inhibitory Processes in Attention, Memory, and Language, eds D. Dagenbach and T. H. Carr (San Diego, CA, USA: Academic Press), 189-239.

Logan, G. D., and Burkell, J. (1986). Dependence and independence in responding to double stimulation: a comparison of stop, change, and dualtask paradigms. J. Exp. Psychol. Hum. Percept. Perform. 12, 549-563.

Logan, G. D., Cowan, W. B., and Davis, K. A. (1984). On the ability to inhibit simple and choice reaction time responses: a model and a method. J. Exp. Psychol. Hum. Percept. Perform. 10, 276-291.

Luce, R. D. (1986). Response Times: Their Role in Inferring Elementary Mental Organization. New York, NY: Oxford University Press.

Luppino, G., Matelli, M., Camarda, R. M., Gallese, V., and Rizzolatti, G. (1991). Multiple representations of body movements in mesial area 6 and the adjacent cingulate cortex: an intracortical microstimulation study in the macaque monkey. J. Comp. Neurol. 311, 463-482.

Miller, E. K., and Cohen, J. D. (2001). An integrative theory of prefrontal cortex function. Annu. Rev. Neurosci. 24, 167-202.

Mink, J. W. (1996). The basal ganglia: focused selection and inhibition of competing motor programs. Prog. Neurobiol. 50, 381-425.

Mirabella, G., Iaconelli, S., Romanelli, P., Modugno, N., Lena, F., Manfredi, M., and Cantore, G. (2012). Deep brain stimulation of subthalamic nuclei affects arm response inhibition in parkinson's patients. Cereb. Cortex 22, 1124-1132.

Mirabella, G., Pani, P., and Ferraina, S. (2008). Context influences on the preparation and execution of reaching movements. Cogn. Neuropsychol. 25, 996-1010.

Mirabella, G., Pani, P., and Ferraina, S. (2011). Neural correlates of cognitive control of reaching movements in the dorsal premotor cortex of rhesus monkeys. J. Neurophysiol. 106, 1454-1466.

Mirabella, G., Pani, P., Paré, M., and Ferraina, S. (2006). Inhibitory control of reaching movements in humans. Exp. Brain Res. 174, 240-255.

Mita, A., Mushiake, H., Shima, K. Matsuzaka, Y., and Tanji, J. (2009). Interval time coding by neurons in 
the presupplementary and supplementary motor areas. Nat. Neurosci. $12,502-507$.

Monakow, K., Akert, K., and Künzle, H. (1978). Projections of the precentral motor cortex and other cortical areas of the frontal lobe to the subthalamic nucleus in the monkey. Exp. Brain Res. 33, 395-403.

Nambu, A. (2004). A new dynamic model of the cortico-basal ganglia loop. Prog. Brain Res. 143, 461-466.

Nambu, A., Takada, M., Inase, M., and Tokuno, H. (1996). Dual somatotopical representations in the primate subthalamic nucleus: evidence for ordered but reversed body-map transformations from the primary motor cortex and the supplementary motor area. J. Neurosci. 16, 2671-2683.

Nelson, M. J., Boucher, L., Logan, G. D., Palmeri, T. J., and Schall, J. D. (2010). Nonindependent and nonstationary response times in stopping and stepping saccade tasks. Atten. Percept. Psychophys. 72, 1913-1929.

Okano, K., and Tanji, J. (1987). Neuronal activities in the primate motor fields of the agranular frontal cortex preceding visually triggered and self-paced movement. Exp. Brain Res. 66, 155-166.

Padoa-Schioppa, C., and Assad, J. A. (2006). Neurons in the orbitofrontal cortex encode economic value. Nature 441, 223-226.

Papa, S. M., Artieda, J., and Obeso, J. A. (1991). Cortical activity preceding self-initiated and externally triggered voluntary movement. Mov. Disord. 6, 217-224.

Paré, M., and Hanes, D. P. (2003). Controlled movement processing: superior colliculus activity associated with countermanded saccades. J. Neurosci. 23, 6480-6489.

Petrides, M., and Pandya, D. N. (1999). Dorsolateral prefrontal cortex: comparative cytoarchitectonic analysis in the human and the macaque brain and corticocortical connection patterns. Eur. J. Neurosci. 11, 1011-1036.

Picton, T. W., Stuss, D. T., Alexander, M. P., Shallice, T., Binns, M. A., and Gillingham, S. (2007). Effects of focal frontal lesions on response inhibition. Cereb. Cortex $17,826-838$

Ratcliff, R. (1978). A theory of memory retrieval. Psychol. Rev. 85, 59-108.

Reddi, B. A., and Carpenter, R. H. (2000). The influence of urgency on decision time. Nat. Neurosci. 3, 827-830.
Roesch, M. R., and Olson, C. R. (2003). Impact of expected reward on neuronal activity in prefrontal cortex, frontal and supplementary eye fields and premotor cortex. J. Neurophysiol. 90, 1766-1789.

Roesch, M. R., and Olson, C. R (2004). Neuronal activity related to reward value and motivation in primate frontal cortex. Science 304, 307-310.

Romo, R., and Schultz, W. (1992). Role of primate basal ganglia and frontal cortex in the internal generation of movements. III. Neuronal activity in the supplementary motor area. Exp. Brain Res. 91, 396-407.

Sakagami, M., Tsutsui, Ki., Lauwereyns, J., Koizumi, M., Kobayashi, S. and Hikosaka, O. (2001). A code for behavioral inhibition on the basis of color, but not motion, in ventrolateral prefrontal cortex of macaque monkey. J. Neurosci. 21, 4801-4808.

Sakagami, M., and Watanabe, M. (2007). Integration of cognitive and motivational information in the primate lateral prefrontal cortex. Ann. N.Y. Acad. Sci. 1104, 89-107.

Sakai, K. (2008). Task set and prefrontal cortex. Annu. Rev. Neurosci. 31, 219-245.

Scangos, K. W., and Stuphorn, V. (2010). Medial frontal cortex motivates but does not control movement initiation in the countermanding task. J. Neurosci. 30, 1968-1982.

Schall, J. D. (1991a). Neuronal activity related to visually guided saccades in the frontal eye fields of rhesus monkeys: comparison with supplementary eye fields. J. Neurophysiol. 66, 559-579.

Schall, J. D. (1991b). Neuronal activity related to visually guided saccadic eye movements in the supplementary motor area of rhesus monkeys. J. Neurophysiol. 66, 530-558.

Schall, J. D. (1997). "Visuomotor areas of the frontal lobe," in Cerebral Cortex, Vol. 4, eds K. S. Rockland, A. Peters, and J. Kaas (New York, NY: Plenum), 527-638.

Schall, J. D., and Boucher, L. (2007). Executive control of gaze by the frontal lobes. Cogn. Affect. Behav. Neurosci. 7, 396-412.

Schlag, J., and Schlag-Rey, M. (1987). Evidence for a supplementary eye field. J. Neurophysiol. 57, 179-200.

Schmidt, L., d'Arc, B. F., Lafargue, G., Galanaud, D., Czernecki, V., Grabli, D., Schüpbach, M., Hartmann, A., Lévy, R., Dubois,
B., and Pessiglione, M. (2008). Disconnecting force from money: effects of basal ganglia damage on incentive motivation. Brain 131, 1303-1310.

Segraves, M. A. (1992). Activity of monkey frontal eye field neurons projecting to oculomotor regions of the pons. J. Neurophysiol. 68, 1967-1985.

Segraves, M. A., and Goldberg, M. E. (1987). Functional properties of corticotectal neurons in the monkey's frontal eye field. $J$. Neurophysiol. 58, 1387-1419.

Sharp, D. J., Bonnelle, V., De Boissezon, X., Beckmann, C. F., James, S. G., Patel, M. C., and Mehta, M. A. (2010). Distinct frontal systems for response inhibition, attentional capture, and error processing. Proc. Natl. Acad. Sci. U.S.A. 107, 6106-6111.

So, N. Y., and Stuphorn, V. (2010). Supplementary eye field encodes option and action value for saccades with variable reward. $J$. Neurophysiol. 104, 2634-2653.

Sohn, J. W., and Lee, D. (2007). Orderdependent modulation of directional signals in the supplementary and presupplementary motor areas. J. Neurosci. 27, 13655-13666.

Sommer, M. A., and Wurtz, R. H. (2000). Composition and topographic organization of signals sent from the frontal eye field to the superior colliculus. J. Neurophysiol. 83, 1979-2001.

Stuphorn, V., and Schall, J. D. (2002). Neuronal control and monitoring of initiation of movements. Muscle Nerve 26, 326-339.

Stuphorn, V., and Schall, J. D. (2006) Executive control of countermanding saccades by the supplementary eye field. Nat. Neurosci. 9, 925-931.

Stuphorn, V., Brown, J. W., and Schall, J. D. (2010). Role of supplementary eye field in saccade initiation: executive, not direct, control. J. Neurophysiol. 103, 801-816.

Stuphorn, V., Taylor, T. L., and Schall, J. D. (2000). Performance monitoring by the supplementary eye field. Nature 408, 857-860.

Sumner, P., Nachev, P., Morris, P., Peters, A. M., Jackson, S. R. Kennard, C., and Husain, M. (2007). Human medial frontal cortex mediates unconscious inhibition of voluntary action. Neuron $54,697-711$.

Tanji, J. (1996). New concepts of the supplementary motor area. Curr. Opin. Neurobiol. 6, 782-787.

Thaler, D., Chen, Y.-C., Nixon, P. D., Stern, C. E., and Passingham, R. E.
(1995). The functions of the medial premotor cortex. I. Simple learned movements. Exp. Brain Res. 102, 445-460.

Thaler, D. E., Rolls, E. T., and Passingham, R. E. (1988). Neuronal activity of the supplementary motor area (SMA) during internally and externally triggered wrist movements. Neurosci. Lett. 93 264-269.

Tremblay, L., and Schultz, W. (1999). Relative reward preference in primate orbitofrontal cortex. Nature 398, 704-708.

Uchida, N., Kepecs, A., and Mainen, Z. F. (2006). Seeing at a glance, smelling in a whiff: rapid forms of perceptual decision making. Nat. Rev. Neurosci. 7, 485-491.

Verbruggen, F., and Logan, G. D. (2008). Response inhibition in the stopsignal paradigm. Trends Cogn. Sci. 12, 418-424.

Verbruggen, F., and Logan, G. D. (2009). Proactive adjustments of response strategies in the stop-signal paradigm. J. Exp. Psychol. Hum. Percept. Perform. 35, 835-854.

Verbruggen, F., Liefooghe, B., and Vandierendonck, A. (2004). The interaction between stop signal inhibition and distractor interference in the flanker and stroop task. Acta Psychol. (Amst.) 116, 21-37.

Verbruggen, F., Liefooghe, B., and Vandierendonck, A. (2006). The effect of interference in the early processing stages on response inhibition in the stop signal task. Q. J. Exp. Psychol. (Hove) 59, 190-203.

Wagenmakers, E.-J., Zeelenberg, R., Steyvers, M., Shiffrin, R., and Raaijmakers, J. (2004). Nonword repetition in lexical decision: support for two opposing processes. Q. J. Exp. Psychol. A 57, 1191-1210.

Wallis, J. D., and Miller, E. K. (2003). Neuronal activity in primate dorsolateral and orbital prefrontal cortex during performance of a reward preference task. Eur. J. Neurosci. 18, 2069-2081.

Yazawa, S., Ikeda, A., Kunieda, T., Ohara, S., Mima, T., Nagamine, T., Taki, W., Kimura, J., Hori, T., and Shibasaki, H. (2000) Human presupplementary motor area is active before voluntary movement: subdural recording of bereitschaftspotential from medial frontal cortex. Exp. Brain Res. 131, 165-177.

van Veen, V., Krug, M. K., and Carter, C. S. (2008). The neural and 
computational basis of controlled speed-accuracy tradeoff during task performance. J. Cogn. Neurosci. 20, 1952-1965.

van den Wildenberg, W. P. M., van Boxtel, G. J. M., and van der Molen, M. W. (2003). The duration of response inhibition in the stop-signal paradigm varies with response force. Acta Psychol. (Amst.) 114, 115-129.

Conflict of Interest Statement: The authors declare that the research was conducted in the absence of any commercial or financial relationships that could be construed as a potential conflict of interest.
Received: 07 February 2012; paper pending published: 24 February 2012; accepted: 29 April 2012; published online: 19 June 2012.

Citation: Stuphorn $V$ and Emeric EE (2012) Proactive and reactive control by the medial frontal cortex. Front. Neuroeng. 5:9. doi: 10.3389/fneng. 2012.00009
Copyright (C) 2012 Stuphorn and Emeric. This is an open-access article distributed under the terms of the Creative Commons Attribution Non Commercial License, which permits non-commercial use, distribution, and reproduction in other forums, provided the original authors and source are credited. 